\title{
ATTITUDES TOWARD THE ROLE OF THE PSYCHOLOGIST AND THE COUNSELOR IN THE SECONDARY SCHOOL'
}

\author{
RICHARD T. KNOWLES \\ University of Michigan \\ BRUGE SHERTZER \\ Purdue University
}

\begin{abstract}
Summary: Attitudes of various professional groups toward the role of the school psychologist were assessed by means of an attitude scale. The scale had also been submitted to other samples of these professional groups to assess their attitudes toward the role of the school counselor. The items were the same except that "the school psychologist" was substituted for "the school counselor." The results of the two administrations of the scale were compared. It was concluded that the professional groups view the counselor and psychologist as having different roles in the school and that separate training programs should continue. However, the existence of "role differentiation" suggests the need for more communication between the counselor and the psychologist in their training programs and in their work in the seconday school.
\end{abstract}

Today, there is much discussion about the functions of various school personnel specialists. The rapid growth of these specialities-school counseling, school psychology, school social work, etc. - has led to many questions. To cite but a few: "Are the various specialities unique in their functions?" "If so, what are these functions?" "Do these functions have to be performed by one person?" "Do school personnel know the differences between the functions of these various specialities?"

Two previous studies (Knowles \& Shertzer, 1965, 1966) investigated attitudes toward the role of the school counselor. In the first study (1965), the attitudes of counselor educators, counselors and school administrators toward the role of the secondary school counselor were investigated. It was found that those with more course work in counseling and guidance viewed the counselor more as a specialist, whereas those with less course work and more secondary school experience perceived him as more of a generalist. Briefly, "specialist" was defined as the secondary school counselor who devoted the major portion of his time to

1This research was supported in part under NIMH Grant \#01428, which was awarded to the Midwest Research Center of the Interprofessional Research Commission on Pupil Personnel Services (IRCOPPS). counseling, while "generalist" was used to designate one who performed many activities in addition to counseling. A general conclusion was that the counselor was trained to be a specialist but hired to be a generalist, and that his own perceptions of his role were somewhat between these two positions.

In the second study (1966), the attitudes of school psychologists toward the role of the secondary school counselor were investigated. Their attitudes seemed to suggest a pattern of role differentiation; i.e., school psychologists tended to identify the counselor with functions different from their own and they emphasized few overlapping functions. The authors concluded from these results that such a viewpoint distorted the reality of the school situation and that it could lead to friction between the two groups.

The aim of this present study was to investigate the attitudes of the same professional groups (counselor educators, school counselors, school psychologists, and school administrators) toward the role of the psychologist in the secondary school and to contrast these attitudes with their attitudes toward the role of the school counselor reported in the previous studies. It would seem to be important to know whether there is a communality in the attitudes of these groups toward the role of the psychologist, since their 
expectations influence the successful performance of the role. If differences do exist, they must be known if they are to be resolved. Further, it would seem important to determine whether the professional groups perceive the role of the school psychologist as being different from the role of the school counselor. If differences do not exist, perhaps the roles are not distinct and could or should be combined. If the roles are perceived to be different, it would again be important to pin-point the differences in order to clarify the implications and to avoid misunderstardings.

\section{METhOD}

The construction and development of the attitude scale used in this study are described adequately in the two previous studies. In essence, the scale provides a total test score which is a measure of a generalist-specialist dimension. High scores indicate a perception of the counselor (psychologist in the present study) as a generalist performing many varied functions in the school; low scores indicate a perception of the counselor (psychologist in the present study) as a specialist limiting himself to counseling. The scale also provides five sub-test scores which were previously arrived at through a factor analysis of the items (Knowles \& Shertzer, 1965). Although the results of this present administration were not factor analyzed, the same factor scores were used as a basis for comparison between the counselor and psychologist roles. The reliability estimates for total score and factor scores in the first study (Knowles \& Shertzer, 1965) were: total score .92, Factor I .82, Factor II .72, Factor III .83, Factor IV .84, Factor V .47. These estimates were derived from six different random samples of 50 each, one sample for each estimate. The samples were then analyzed using Hoyt's (1941) analysis of variance method for estimating reliability.
The attitude scale used in this study is the same as the one used in the two previous studies except that "the school psychologist" was substituted for "the school counselor." The scale was mailed (during 1966-67) to 200 members of the Association for Counselor Education and Supervision, 200 members of the American School Counselor Association, 200 members of the American Psychological Association-Division of School Psychology, and 200 members of the American Association for School Administrators. Usable returns were received from $108(54 \%)$ ACES members, $101 \quad(51 \%)$ ASCA members, 128 (64\%) APA-Division 16 members, and 108 (54\%) AASA members. This rate of return is roughly comparable with that of the previous studies $(57-60 \%)$. Two-tailed t-tests were used in all comparisons and differences reported were significant at least at the .05 level.

\section{RESULTS}

\section{Attitudes Toward the Role of the School Psychologist}

Table 1 presents the results obtained for each of the groups on total attitude scale score and factor scores. Total score was obtained by adding the scores on each of the items on the scale.

Means for the total score for the present administration follow the same pattern as that of the 1966 study from low to high in the following order: ACES (counselor educators), ASCA (counselors), APA (school psychologists), AASA (school administrators) except that the positions of the ASCA members and ACES members reversed. In both studies, school administrators perceived the school counselor and the school psychologist as more of a generalist than did members of either of these groups perceive themselves. ( $p<.001$-APA Div. 16 members compared with AASA members). In contrast, total test comparisons show that school psychologists viewed themselves as generalists to a greater degree than 
Table 1 Distributions of Various Groups on Psychologist Scale Total Score
and Factor Scores

\begin{tabular}{lcccccccccccc}
\hline Group & Total & Test $^{2}$ & Factor & $\mathbf{I}^{2}$ & Factor & II $^{8}$ & Factor & III* & Factor & IV & Factor & V* \\
& Mean & SD & Mean & SD & Mean & SD & Mean & SD & Mean & SD & Mean & SD \\
\hline
\end{tabular}

Assoc. for

Counselor

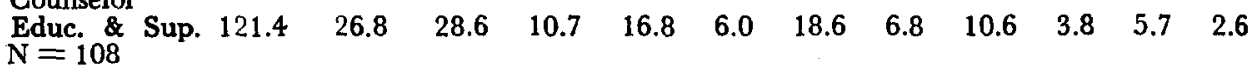

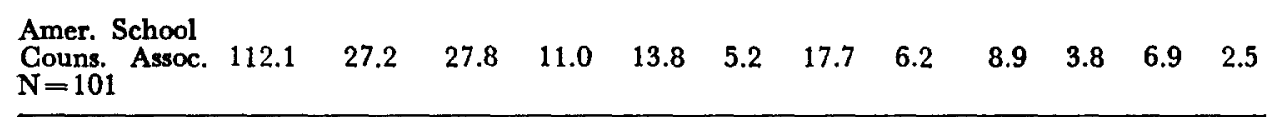

Amer. Psych.

Assoc., Div.

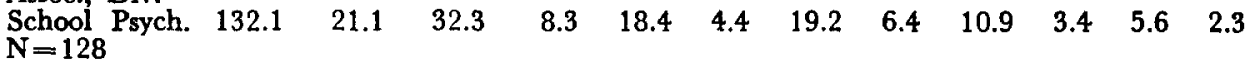

Amer. Assoc.

$\begin{array}{llllllllllll}\text { School Admin. } 141.8 & 20.0 & 34.7 & 9.1 & 18.6 & 5.5 & 25.1 & 5.3 & 9.6 & 3.4 & 6.9 & 2.6\end{array}$

$\mathrm{N}=108$

1. Low score tends to specialist position; high score to generalist position.

2. Low score tends to narrow role definition; high score to broad role definition.

3. Low score tends to non-authoritarian, student-centered, full-time counselor; high score to somewhat authoritarian, institution-centered, part-time counselor.

4. Low score tends to psychological viewpoint; high score to educational viewpoint.

5. Low score tends to clinical approach; high score to non-clinical approach.

6. Low score tends to personal and educational counseling; high score to informationgiving.

did counselors or counselor educators (with both comparisons at the .001 level of significance).

This finding might reflect a growing desire of school psychologists to broaden or change their role or it might reflect the role differentiation phenomenon described previously. That is, in the same way school psychologists identified counselors with functions different from their own, counselors in this study seem to be identifying the school psychologist's role as more of a speciality than either school psychologists define it $(p<.001)$ or even more than counselor educators define it $(p<.05)$. The fact that counselors must work directly with school psychologists may explain their greater desire to differentiate between the two roles and to perceive the school psychologist as more of a specialist. The overlapping areas between the two roles are minimized.

The pattern for total score also holds for Factor I (administrative responsibilities), i.e., administrators perceived school psychologists as taking more administrative responsibilities than did psychologists themselves $(p<.05)$ or the other groups. Psychologists perceived themselves as assuming more administrative responsibilities in the school than either counselor educators $(\mathrm{p}<.01)$ or school counselors ( $\mathrm{p}<.001)$ believed they should. This pattern-ASCA, ACES, APA-Div. 16, AASA, from low to high-is the same as that of total score with the exception that ACES and ASCA mem- 
bers did not differ significantly on Factor I. Presumably, the school psychologist's desire to broaden his role coupled with role differentiation on the part of the counselors and counselor educators account for this pattern.

A low score on Factor II tends to a perception of the school psychologist as a non-authoritarian, student-centered, full-time counselor and a high score to a perception of the school psychologist as a somewhat authoritarian, institution-centered, part-time counselor. School psychologists and administrators identified the school psychologist with school and society and with noncounseling duties more than counselors or counselor educators did $(p<.001$ and $\mathrm{p}<.05$ respectively). These results are also consistent with the explanation given above. The counselors, in restricting the role of the psychologist to specific one-to-one situations, also attributed to him attitudes consistent with a special role (more identification with the student than with the "system").

High scores on Factor III (discipline commitment) reflect an educational viewpoint, emphasizing teaching experience, education courses and educational functions of the school psychologist; low scores indicate more of a psychological viewpoint (psychology courses, experience, etc.). Administrators on this factor identified the school psychologist with education more than did the other groups $(\mathrm{p}<.001)$. Psychologists, counselor educators, and counselors did not differ from one another in this factor. It would seem that the specialists understand one another's training better than the administrators who hire them.

A high score on Factor IV (clinical emphasis) indicates a non-clinical approach; low scores indicate a clinical aproach, emphasizing clinical psychology courses and clinical work with emotionally disturbed students. Counselor educators and psychologists emphasized the clinical approach less than did counselors $(p<.001)$ and administrators $(p<.01)$. A combination of role differentiation (for the counselors) and a need to take care of emotionally disturbed students (for the administrators) may account for this difference.

High scores on Factor $\mathrm{V}$ (type of student contact) reflect an emphasis on the information-giving role of the psychologist; low scores indicate an emphasis on personal and educational counseling. Again, psychologists and counselor educators differed from the other two groups in emphasizing a personal and educational counseling role for the school psychologist more than counselors $(\mathrm{p}<.001)$ or administrators $(\mathrm{p}<.001)$. Both psychologists and counselor educators viewed the school psychologist as working in these areas, but not in an information-giving role.

To summarize briefly, administrators tended to see the school psychologist not only as a generalist who has some administrative responsibility and who is identified with education by training and experience, but also as a specialist who can cope with or treat emotionally disturbed students. Administrators' expectations for the school psychologist seem broader than those of the other groups. Their unfamiliarity with the various specialities as well as the great range of school problems they have to contend with might account for their expectations.

Psycologists identifed themselves less. with education than school administrators might wish and saw themselves working with a greater range of students than administrators believed they should. Psychologists did view themselves as generalists in the total educational setting but as specialists with disturbed students. However, they were more modest in their perceptions of these two functions than were administrators.

Counselors tended to identify school psychologists as specialists with a clin- 
ical orientation possessing depth in psychological preparation. Counselors did not view them as generalists in the schools as much as did psychologists themselves or school administrators. The tendency of one specialist protectively to differentiate his role from another specialist may account for this pattern.

Generally, counselor educators wavered back and forth between the views of counselors and psychologists. By training, counselor educators are similar to school psychologists; profession- ally, they are associated more with counselors.

Comparison of School Counselor and School Psychologist Roles

Data reported in Table 2 show the comparative distributions of the various professional groups on the first administration of the scale (counselor role) and the second administration (psychologist role). The same items were used in both administrations except for changes in title and other appropriate terminology.

Table 2

Distributions of Group Scores on Counselor and Psychologist Scales ${ }^{1}$

\begin{tabular}{|c|c|c|c|c|c|c|c|c|c|c|c|c|}
\hline Group/Scale & $\begin{array}{l}\text { Total } \\
\text { Mean }\end{array}$ & $\begin{array}{l}\text { Score }^{1} \\
\text { SD }\end{array}$ & $\begin{array}{l}\text { Factor } \\
\text { Mean }\end{array}$ & $\begin{array}{l}\mathrm{I}^{2} \\
\mathrm{SD}\end{array}$ & $\begin{array}{l}\text { Factor } \\
\text { Mean }\end{array}$ & $\begin{array}{l}\mathrm{II}^{3} \\
\mathrm{SD}\end{array}$ & $\begin{array}{l}\text { Factor } \\
\text { Mean }\end{array}$ & $\begin{array}{l}\mathrm{III}^{+} \\
\mathrm{SD}\end{array}$ & $\begin{array}{l}\text { Factor } \\
\text { Mean }\end{array}$ & $\begin{array}{l}\text { IV' } \\
\text { SD }\end{array}$ & $\begin{array}{l}\text { Factor } \\
\text { Mean }\end{array}$ & $\begin{array}{l}\mathrm{V}^{\mathrm{B}} \\
\mathrm{SD}\end{array}$ \\
\hline \multirow{2}{*}{$\begin{array}{l}A C E S \\
\text { Couns. Scale } \\
(\mathrm{N}=291) \\
\text { Psych. Scale } \\
(\mathrm{N}=108)\end{array}$} & 152.8 & 30.7 & 47.0 & 12.2 & 15.7 & 5.8 & 24.7 & 8.8 & 17.3 & 4.7 & 5.1 & 2.7 \\
\hline & 121.4 & 26.8 & 28.6 & 10.7 & 16.8 & 6.0 & 18.6 & 6.8 & 10.6 & 3.8 & 5.7 & 2.6 \\
\hline \multirow{2}{*}{$\begin{array}{l}A S C A \\
\text { Couns. Scale } \\
\text { (N=289) } \\
\text { Psych. Scale } \\
(\mathrm{N}=101)\end{array}$} & 158.8 & 26.6 & 53.6 & 10.1 & 14.1 & 5.2 & 26.7 & 7.4 & 15.2 & 4.5 & 6.8 & 2.6 \\
\hline & 112.1 & 27.2 & 27.8 & 11.0 & 13.8 & 5.2 & 17.7 & 6.2 & 8.9 & 3.8 & 6.9 & 2.5 \\
\hline \multirow{2}{*}{$\begin{array}{l}\text { APA-Div. 16 } \\
\text { Couns. Scale } \\
\text { (N=74) } \\
\text { Psych. Scale } \\
(\mathrm{N}=128)\end{array}$} & 165.5 & 23.6 & 52.8 & 9.4 & 17.0 & 4.7 & 25.4 & 7.1 & 19.5 & 4.8 & 13.2 & 2.3 \\
\hline & 132.1 & 21.1 & 32.3 & 8.3 & 18.0 & 4.4 & 19.2 & 6.4 & 10.9 & 3.4 & 5.6 & 2.3 \\
\hline \multirow{2}{*}{$\begin{array}{l}\text { AASA } \\
\text { Couns. Scale } \\
(\mathrm{N}=287) \\
\text { Psych. Scale } \\
(\mathrm{N}=108)\end{array}$} & 183.9 & 24.4 & 59.5 & 8.5 & 20.1 & 5.7 & 32.7 & 4.7 & 14.0 & 4.3 & 7.2 & 2.3 \\
\hline & 141.8 & 20.0 & 34.7 & 9.1 & 18.6 & 5.5 & 25.1 & 5.3 & 9.6 & 3.4 & 6.9 & 2.6 \\
\hline
\end{tabular}

1. Original scale dealt with role of the counselor in the secondary school; revised scale dealt with role of the psychologist in the secondary school. The same items were employed except for change in title.

2. Low score tends to narrow role definition; high score to broad role definition.

3. Low score tends to non-authoritarian, student-centered, full-time counselor; high score to somewhat authoritarian, institution-centered, part-time counselor.

4. Low score tends to psychological viewpoint; high score to educational viewpoint.

5. Low score tends to clinical approach; high score to non-clinical approach.

6. Low score tends to personal and educational counseling; high score to informationgiving. 
Within the groups, the same general pattern from low to high existed. These groups viewed the roles of the counselor and psychologist differently; the school psychologist was seen as more of a specialist. It may be argued that since the scale was originally designed to assess the counselor's role, it necessarily failed to include many activities appropriate to the psychologist's role. This objection, however, does not alter the conclusion that each of these professional groups views the role of the counselor as being different from the role of the school psychologist. Many perceptions, some historically derived, differentiate the two roles. It would not be easy to break down these perceptions or to propose that one person enact both roles.

More specifically, each of the groups -counselor educators, counselors, school psychologists, and school administrators-viewed the counselor, more than the school psychologist, as associated with administrative responsibilities in the school. While the withingroups pattern was roughly the same (low to high), each group expected the counselor to perform a significantly broader range of duties than they expect of school psychologists. Perhaps if the scale had included activities more appropriate to the role of the psychologist, these groups would have assigned him more general responsibility. It is obvious, though, that certain activities of the school counselor, such as setting up college nights, carerr days, providing scholarship information, etc., are seen as unique to his role.

Data about Factor II reflect the greatest perceived similarities between the counselor and psychologist roles. This factor (non-authoritarian, student-centered full-time counselor vs. somewhat authoritarian, institutioncentered part-time counselor) contains items which seem to reflect attitudes toward the specialist-administrator relationship regardless of the type of specialty. Each of the groups saw little difference between the counselor and the psychologist in regard to their relationship to the school.

Based upon data pertinent to Factor III, (education vs. psychology), each group viewed school psychologists as being more closely identified with psychology than were school counselors. They saw counselors, more so than psychologists, as having teaching experience, being prepared through education courses, and, in general, being identified with education.

On the question of working with emotionally disturbed children (Factor IV, clinical emphasis), all groups shared the attitude that school psychologists should work with such students more than should school counselors. Psychologists themselves concur with this attitude and this activity is probably a major differentiation between the two roles.

Few differences existed between the two attitude scale administrations, when data are compared on the question of student contact (see Factor V, Table 2). However, psychologists viewed the counselor as providing an informationgiving service significantly more than they (psychologists) and significantly more than all other groups thought counselors should. Even counselors did not stress the information-giving aspect of their roles as much as did school psychologists.

In summary, each group viewed the role of counselor and the role of psychologist as differing in several respects. Specifically, they associated counselors with administrative responsibilities, believed that counselors are identified more with education rather than with psychology, and were of the opinion that counselors work with "normal" students more than with emotionally handicapped students. Each group saw little difference between the counselor and the psychologist in their relationship to the "system" of the school and, in general, 
perceived them as similar with regard to the information giving role.

\section{Summary of Results}

This study was undertaken to describe the attitudes of significant professional groups (counselors, counselor educators, school psychologists, school administrators) toward the role of the school psychologist in the secondary school. A second purpose was to compare the attitudes of these groups toward the role of the school psychologist with their attitudes toward the role of the school counselor.

The following is a summary of the groups' attitudes toward the role of the school psychologist:

1. School administrators tended to view the school psychologist as having a broader, more general role in the school than psychologists assigned to themselves or that counselors and counselor educators assigned to them.

2. The phenomenon of role differentiation seems to be operating for counselors and, to some extent, for counselor educators; both of these groups tended to differentiate the school psychologist's role from the school counselor's role to a greater extent than did the other groups.

3. Counselors, counselor educators and school psychologists agreed that the school psychologist is identified more with psychology than with education.

4. All groups seemed to agree in identifying the school psychologist as a specialist in working with disturbed children but those with more training in the area (psychologists and counselor educators) did not put as heavy an emphasis on this activity for the psychologist as did administrators and counselors.

5. School psychologists seemed to want to become less specialized in their activities. However, the general activities they proposed are probably not the ones administrators have in mind for them. For example, psychologists might want to consult more with others in the school but would probably resist general administrative or teaching duties.

When comparing the attitudes of these professional groups toward the role of the school psychologist with their attitudes toward the role of the school counselor, the following summary emerges:

1. All groups viewed the school psychologist's role as different from the school counselor's role with regard to most issues dealt with in the questionnaires. Counselors were perceived by these groups as performing more generalisttype duties than psychologists.

2. Counselors were identified more with education and psychologists more with the discipline of psychology.

3. Counselors were perceived as working more with normal students and psychologists as working more with disturbed students.

4. Even though the perceptions concerning these two specialities were significantly different on most issues, the range of the scores would indicate an overlapping rather than a dichotomous relationship between the two roles.

\section{Conclusions}

In considering the roles of professional groups, the major traditional function for which they exist is sometimes subordinate to the personal preferences of the professionals themselves. Counselors and psychologists exist to offer service to students; how can their activities be coordinated so as to serve students better? Obviously, by estab- 
lishing better communication between these two specialists and their administrators. The area of perceived overlapping services affords an opportunity for cooperation and increased communication rather than representing excessive duplication of service. Coordination between the two specialities should be developed in training institutions if it is to be implemented in practice. The phenomenon of role differentiation common to both groups is an indication that there is a lack of understanding and communication between them.

Currently, it would not seem feasible to merge the two specialities. Counselors and psychologists view their roles as being different, as do administrators and counselor educators. Presumably, their training programs, their clientele, and their functions differ. However, it would seem most appropriate to strengthen and support these groups in the activities they perform best and, simultaneously, to increase opportunities for better communication and cooperation between them.

\section{REFERENGES}

Hoyt, C. Test reliability estimated by analysis of variance. Psychometrika, 1941, 6, 153-160.

KnOWLrs, R. T., \& Shertzer, B. Attitudes toward the school counselor's role. Counselor Education and Supervision, 1965, 5, 9-20.

Knowies, R. T., \& Shretzer, B. Attitudes of school psychologists toward the role of the secondary school counselor. Journal of School Psychology, 1966, 4, 30-36.

Richard T. Knowles

Assistant Professor

School of Education

University of Michigan

Ann Arbor, Michigan 48104

Bruce Shertzer

Professor of Education

School of Education

Purdue University

Lafayette, Indiana 47907

Received: November 20, 1967

Revision Received: January 29, 1968 